\title{
ANÁLISE DOS CASOS NOTIFICADOS DE VIOLÊNCIA CONTRA MULHER
}

\author{
Paulo Roberto de Mattos ${ }^{1}$, Ivoney da Silva Ribeiro ${ }^{2}$, Vania Carla Camargo ${ }^{3}$
}

\begin{abstract}
RESUMO: A violência é uma das principais causas de morbimortalidade no mundo e considerada problema de saúde pública. Esta pesquisa documental avaliou aspectos epidemiológicos, clínicos e sociodemográficos de mulheres vítimas de violência entre 200 casos notificados, de março de 2009 a abril de 2010, no município de Pinhais - Paraná. Os resultados mostram que a maioria das agressões foi causada pelo próprio companheiro, contra mulheres jovem e com baixo grau de escolaridade; o tempo de sujeição mais frequente à situação de violência variou entre três e quatro anos. As agressões ocorreram mais frequentemente em dois bairros do município e no domicílio da vítima e caracterizaram-se por agressões físicas e psicológicas; o emprego da força física foi mais comum, membros e cabeça foram mais atingidas pela ação. A maioria das vítimas não opinou sobre o desejo, ou não, de reconciliação com o agressor. A análise permitiu caracterizar a violência contra a mulher no município.
\end{abstract}

PALAVRAS-CHAVE: Violência contra a mulher; Notificação de abuso; Enfermagem em saúde pública.

\section{ANALYSIS OF NOTIFIED CASES OF VIOLENCE AGAINST WOMEN}

ABSTRACT: Violence is one of the principal causes of morbidity and mortality in the world and is considered a public health problem. This documental research evaluated epidemiological, clinical and sociodemographic aspects of women who were victims of violence in 200 notified cases in March and April 2010 in the municipality of Pinhais in Paraná. The results show that the majority of the cases of aggression were caused by the woman's own partner, against women who were young and with a low level of education; the most frequent duration of the subjection to the situation of violence varied between three and four years. Aggression occurred most frequently in two neighborhoods of the municipality, and in the victim's home, being characterized by physical and psychological aggression; the use of physical force was most common, with limbs and head being most affect by the actions. The majority of the victims did not express an opinion about the desire or not for reconciliation with the aggressor. The analysis permitted the characterization of violence against women in the municipality.

KEYWORDS: Violence against women; Notification of abuse; Public health nursing.

\section{ANÁLISIS DE LOS CASOS NOTIFICADOS DE VIOLENCIA CONTRA MUJER}

RESUMEN: La violencia es una de las principales causas de morbimortalidad en el mundo, siendo considerada problema de salud pública. Esta investigación documental evaluó aspectos epidemiológicos, clínicos y sociodemográficos de mujeres víctimas de violencia entre 200 casos notificados, de marzo de 2009 a abril de 2010, en el municipio de Pinhais - Paraná. Los resultados muestran que la mayoría de las agresiones fue causada por el propio compañero, contra mujeres jóvenes y con bajo grado de escolaridad; el tiempo de sujeción más frecuente a la situación de violencia ha variado entre tres y cuatro años. Las agresiones ocurrieron de modo más frecuente en dos barrios del municipio y en el domicilio de la víctima; se caracterizan como agresiones físicas y psicológicas; el uso de la fuerza física fue más común; miembros y cabeza fueron más atingidos por la acción. La mayoría de las víctimas no opinó sobre el deseo, o no, de reconciliación con el agresor. El análisis permitió caracterizar la violencia contra la mujer en el municipio.

PALABRAS CLAVE: Violencia contra la mujer; Notificación de abuso; Enfermería en salud pública.

\footnotetext{
${ }^{1}$ Enfermeiro da Secretaria da Família e Desenvolvimento Social de Curitiba.

${ }^{2}$ Enfermeiro da Santa Casa de Misericórdia de Curitiba.

${ }^{3}$ Enfermeira. Mestre em Tecnologia em Saúde. Professora do Curso de Graduação em Enfermagem das Faculdades Integradas do Brasil - UniBrasil.
} 


\section{INTRODUÇÃO}

A violência é uma das principais causas de morbidade e mortalidade em todo mundo, apresentando diversas facetas que afetam, de modo diferenciado, a população. Dessa forma, é considerada um problema de saúde pública no mundo e, particularmente, no Brasil ${ }^{(1-2)}$.

A Organização Mundial da Saúde, em 2002, definiu violência como:

O uso intencional da força física ou do poder, real ou em ameaça, contra si próprio, contra outra pessoa, ou contra grupo ou uma comunidade, que resulte ou tenha grande possibilidade de resultar, uma lesão, morte, dano psicológico, deficiência de desenvolvimento ou privação ${ }^{(3: 17)}$.

A violência contra a mulher desdobra-se em casos perversos e cruéis que acontecem cotidianamente, acometendo a vítima de diferentes classes sociais, culturais, étnicas e religiosas, não se importando com as condições socioeconômicas e políticas, revelando assim, a complexidade do tema. A violência, na contemporaneidade, ocupa lugar prioritário na pauta dos problemas sociais ${ }^{(4-5)}$.

A Conferência das Nações Unidas sobre direitos humanos reconheceu a violência contra a mulher como uma violação aos direitos humanos. A partir daí, os países membros das Organizações das Nações Unidas (ONU) têm lutado para a erradicação desse tipo de violência e este fato também é apontados por outros autores ${ }^{(5)}$. Percebe-se que a violência é um tema bastante complexo, pois engloba diversas áreas e envolve determinantes sociais e condicionantes culturais que podem significar agravo à saúde, condições de trabalho, relações interpessoais, qualidade da existência e ameaça à vida. A violência é uma somatória de diversos fatores e é pouco provável que somente um fator, isoladamente, desencadeie o ato violento.

A violência contra a mulher é uma violação dos direitos humanos e às liberdades fundamentais e limita total, ou parcialmente, o reconhecimento, gozo e exercício de tais direitos e liberdades ${ }^{(2)}$.

Estima-se que a violência sexual acometa 12 milhões de pessoas a cada ano, em todo mundo; o agressor, frequentemente, é próximo e conhecido da mulher. No Japão, $75 \%$ foram submetidas a alguma forma de violência física, psicológica ou sexual pelo companheiro. Taxas igualmente expressivas foram reportadas em Porto rico (58\%); Nicarágua (52\%); Bolívia (46\%); Quênia (42\%); Colômbia (40\%); Brasil (38\%); Canadá (29\%); Chile $(26 \%)^{(6)}$.
Inversamente ao que se pensa, a violência contra a mulher não diminui, necessariamente, durante a gravidez. De fato, no Brasil cerca de $13 \%$ das mulheres relatam aumento da freqüência ou maior agressividade da violência durante a gestação ${ }^{(7)}$.

O Instituto Brasileiro de Geografia e Estatística, em 1988, realizou a primeira pesquisa sobre violência doméstica. $\mathrm{O}$ estudo mostrou que $63 \%$ das vítimas eram mulheres e, em mais de $70 \%$ dos casos, o agressor era seu marido ou companheiro. No Brasil, em 2001, a Fundação Perseu Abramo realizou a pesquisa 'A Mulher Brasileira nos Espaços Públicos e Privados', a qual mostrou novos achados sobre a violência contra a mulher, entre os dados está o de que $43 \%$ das brasileiras teriam sido alvo de violência em alguma fase da vida ${ }^{(8)}$.

Entretanto, destaca-se que, em virtude de diversos fatores, os sub-registros são comuns e, consequentemente, as estatísticas não expressam a totalidade dos agravos à saúde da mulher, tendo como causa a violência. O que dificulta que as vítimas denunciem a violência sofrida, ou busquem assistência medica, é a proximidade com o agressor. Isso também decorre da censura social, da vergonha e da humilhação em tornar público o fato e ao fato de muitas mulheres não reconhecem como violência as agressões a que são submetidas por parceiros, pais, irmãos e outros parentes próximos ${ }^{(5)}$.

Outra questão que dificulta a denúncia é a desqualificação dos profissionais e dos serviços de saúde para perceber a violência como uma questão de saúde e como geradora de diversos agravos à saúde. Também há o medo por parte dos profissionais de saúde durante a notificação, principalmente quando essas são mulheres, pois receiam ser vítimas dos agressores denunciados ${ }^{(4,9)}$.

Considerando o exposto e sabendo-se que em Pinhais, Município da Região Metropolitana de Curitiba - Paraná, a violência doméstica se faz presente, torna-se relevante realizar o levantamento e a análise dos casos notificados de violência contra a mulher, objetivo deste estudo.

\section{MÉTODO}

Esta pesquisa caracteriza-se como documental, restropectiva, descritiva, com abordagem quantitativa e de natureza aplicada ${ }^{(10)}$. Esta escolha se justifica devido às características do objeto de estudo e dos objetivos da pesquisa. O estudo documental define-se como um meio de coleta de informações restrito a documentos, que podem ser escritos ou não, formando as fontes primárias, as quais podem ser feitas no ato do acontecimento ou posteriormente ${ }^{(11)}$. 
Este estudo foi submetido ao Comitê de Ética em Pesquisa das Faculdades Integradas do Brasil, com parecer favorável, sob o protocolo número 051/2009. Foi foi realizado por meio do levantamento e análise dos casos notificados, ao Centro de Referência Especializado de Assistência Social (CREAS), de violência contra a mulher, na faixa etária compreendida entre 18 a 59 anos, entre março de 2009 e abril de 2010, totalizando 200 casos notificados. O município do estudo possui uma população 35.250 mulheres na faixa etária do estudo ${ }^{(12)}$.

Foram coletadas informações sobre as seguintes características sociodemográficas da mulher vitimizada: idade, estado civil, escolaridade, ocupação/profissão da vítima, tipo de agressão, consequências físicas das agressões sofridas, meio de violência empregado, região corporal atingida, tempo de submissão às agressões, vínculo com o agressor, desejo de reconciliação com o agressor, meses do ano de maior incidência de casos de agressões e área geográfica do município com maior incidência de casos notificados. Foi realizada a leitura das informações coletadas tratando-as com estatística descritiva para estudo das variáveis ${ }^{(13)}$; os dados foram processados eletronicamente com a utilização do Software Microsoft Office Excel 2007.

\section{RESULTADOS}

Entre os 200 casos notificados no período, a maioria (117 casos/58\%) era casada, cujo marido ou companheiro foi o agressor (165 casos/82,5\%). Nos demais casos 35 $(16,5 \%)$, dividiram-se em agressões perpetradas pelo próprio filho, pelo marido ou companheiro após a separação, pelo irmão, por parente, pelo chefe, pelo pai ou padrasto, pela mãe ou madrasta e por amigo ou conhecido. É importante ressaltar que destes 35 casos, apenas $1 \%$ foi praticado por pessoa desconhecida e 12 casos (6\%) não foi registrado $\mathrm{o}$ vínculo do agressor com a vítima. Em relação à idade das mulheres vitimizadas observou-se maior frequência na faixa etária compreendida entre 25 e 31 anos (23\%), e cuja escolaridade prevalente, quando informada, foi de ensino médio (50 casos/25\%) (Tabela 1).

O tempo de sujeição à agressão entre 3 a 4 anos $(33,5 \%)$ foi o mais frequente (Quadro 1); a análise do registro demonstrou que 15 mulheres $(7,5 \%)$ desejavam reconciliação com o agressor, 39 (19,5\%) não desejavam e 146 (73\%) não responderam ou não opinaram a respeito. Quando na análise da renda familiar, a maioria das vítimas estava na faixa entre um a dois salários mínimos 42\% (21 casos). Vale ressaltar que dos 200 casos notificados, apenas 50 forneceram essa informa- ção e entre esses $19 \%$ moravam em casas alugadas e possuíam, em média, dois filhos por família.

Quanto ao tipo de agressão houve maior prevalência da agressão física e psicológica associadas, num total de 91 casos $(56,8 \%)$. Percebe-se, também, que a violência física, na maioria dos casos, esteve associada com outros tipos de violência, além da psicológica, o que evidencia que a violência física está presente em

Tabela 1 - Características biosociodemográfica dos casos de violência contra a mulher notificados, março 2009 - abril de 2010. Pinhais, 2011

\begin{tabular}{lcc}
\hline Faixa etária (anos) & N & $\mathbf{\%}$ \\
\hline 18 a 24 & 20 & 10,0 \\
25 a 31 & 46 & 23,0 \\
32 a 38 & 33 & 16,0 \\
39 a 45 & 33 & 16,0 \\
46 a 52 & 17 & 9,0 \\
53 a 59 & 11 & 6,0 \\
Ignorada & 40 & 20 \\
\hline Escolaridade & $\mathbf{N}$ & $\mathbf{\%}$ \\
\hline Ensino Médio completo & 31 & 15,5 \\
Ensino Fundamental imcompleto & 27 & 13,5 \\
Ensino Superior completo & 4 & 2,0 \\
Ensino Superior incompleto & 1 & 0,5 \\
Ensino Médio incompleto & 1 & 0,5 \\
Ignorada & 114 & 57,0 \\
\hline Estado Civil & $\mathbf{N}$ & $\mathbf{\%}$ \\
\hline Casada / união estável & 116 & 58,0 \\
Solteira & 22 & 11,0 \\
Separada / divorcida & 8 & 4,0 \\
Viúva & 4 & 2,0 \\
Ignorada & 50 & 25,0 \\
\hline Profissão / Ocupação da Vítima & $\mathbf{N}$ & $\mathbf{\%}$ \\
\hline Empregada & 57 & 28,5 \\
Autônoma & 18 & 9,0 \\
Do lar & 17 & 8,5 \\
Doméstica & 12 & 6,0 \\
Desempregada & 11 & 5,5 \\
Outros & 9 & 4,5 \\
Ignorada & 68 & 34,0 \\
\hline Profissão / Ocupação do Agressor & $\mathbf{N}$ & $\mathbf{\%}$ \\
\hline Trabalho eventual & 37 & 18,5 \\
Pedreiro & 14 & 7,0 \\
Empresário / comerciante & 6 & 3,0 \\
Autônomo & 5 & 2,5 \\
Motorista / moto boy & 5 & 2,5 \\
Operador de máquinas & 5 & 2,5 \\
Vigilante / segurança & 4 & 2,0 \\
Ignorado & 123 & 61,5 \\
\hline
\end{tabular}


mais de $70 \%$ dos registros e, em poucos casos, isoladamente (Quadro 1).

O emprego da força física predominou (49 casos/24,5\%), sendo aplicada isoladamente ou associada com outros meios. A região corporal mais frequentemente atingida foi a cabeça, com 41 registros $(20,5 \%)$ seguida dos membros (39 casos/19,5\%); essas regiões aparecem de forma isolada ou acompanhada com le-

Quadro 1- Idade de mulhers vítimas, tipo de violência sofrida e tempo de submissão à situação de violência, março 2009 - abril de 2010. Pinhais, 2011*

\begin{tabular}{|c|c|c|c|c|c|c|c|c|c|c|c|c|}
\hline & \multicolumn{5}{|c|}{ TIPO DE VIOLÊNCIA SOFRIDA } & \multicolumn{7}{|c|}{ TEMPO QUE SOFRE AGRESSÃO (EM ANOS) } \\
\hline $\begin{array}{c}\text { IDADE } \\
\text { DA } \\
\text { VÍTIMA } \\
\text { (em anos) }\end{array}$ & $\begin{array}{c}\text { física } \\
\mathrm{e} \\
\text { psicol } \\
* *\end{array}$ & $\begin{array}{c}\text { física } \\
\text { e se- } \\
\text { xual e } \\
\text { psicol } \\
* *\end{array}$ & 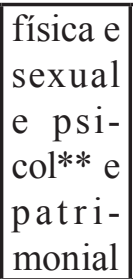 & $\begin{array}{l}\text { único } \\
\text { tipo de } \\
\text { violên- } \\
\text { cia }\end{array}$ & Total & 0 a 2 & 3 a 4 & 5 a 6 & 7 a 8 & 9 a 10 & $>10$ & Total \\
\hline 18 a 24 & 9 & 2 & 2 & 7 & 20 & 8 & 12 & 1 & -- & - & -- & 21 \\
\hline 25 a 31 & 30 & 2 & -- & 14 & 46 & 11 & 21 & 5 & 2 & 1 & -- & 40 \\
\hline 32 a 38 & 15 & 3 & 6 & $\overline{9}$ & 33 & 13 & 12 & 2 & 3 & 1 & 2 & 33 \\
\hline 39 a 45 & 21 & 2 & 1 & 9 & 33 & 6 & 13 & 3 & 2 & 2 & 4 & 30 \\
\hline 46 a 52 & 9 & 2 & -- & 6 & 17 & 1 & 8 & 1 & -- & -- & 6 & 16 \\
\hline 53 a 59 & 7 & 1 & 1 & 2 & 11 & 4 & 1 & -- & 1 & -- & 3 & 9 \\
\hline TOTAL & 91 & 12 & 10 & 47 & 160 & 43 & 67 & 12 & 8 & 4 & 15 & 149 \\
\hline$\%$ & 56,8 & 7,5 & 6,3 & 29,4 & 100 & 28,9 & 45,0 & 8,0 & 5,4 & 2,7 & $\overline{10,0}$ & 100 \\
\hline
\end{tabular}

*Nesta análise comparativa não foram considerados os dados não informados ou ignorados. Por esta razão o total obtido é inferior ao número de casos notificados. **Psicológica.

sões em outras áreas do corpo, como tórax e pescoço. Como consequências das agressões, os dados mostram que 23 casos $(11,5 \%)$ as mulheres apresentam hematomas como principal queixa de lesão (Quadro 2).

Houve maior prevalência de agressões entre os meses de novembro/2009 e março/2010 com, respectivamente, $37(18,5 \%)$ e 34 (17\%) casos notificados; a média de notificação nos demais meses foi de 14 casos (7\%).

Em relação às regiões onde ocorreu violência contra a mulher, o maior número deu-se nos bairros Jardim Weissópolis e Maria Antonieta, com 30 (15\%) e 28 casos (14\%), respectivamente, contra a média de 5.8 casos $(2,9 \%)$ nos demais bairros. O principal local de ocorrência da violência foi o domicílio da vítima.

\section{DISCUSSÃO}

Os casos de agressão reiteram estudos ${ }^{(1,4,14-15)}$ que evidenciam elevada incidência de violência no ambiente doméstico, contra mulheres adultas jovens ${ }^{(16)}$, o que significa a faixa economicamente mais ativa entre as mulheres $(28,5 \%)$. Isto vem ao encontro dos dados do Banco Mundial e do Banco Interamericano de Desenvolvimento, os quais apresentam que um em cada cinco dias de falta ao trabalho no mundo é causado pela violência doméstica ${ }^{(5)}$.
A faixa etária acometida reitera como um dos fatores desencadeantes da violência doméstica o ciúme, seja pela beleza da mulher, sua posição no mercado de trabalho ou sua busca pela independência econômica ${ }^{(17-18)}$. A baixa escolaridade constitui condição da mulher vitimizada ${ }^{(16)}$, embora agressões ocorram com mulheres de todos os níveis educacionais ${ }^{(14)}$.

Em relação ao vínculo do agressor com a vítima, na grande maioria dos casos a violência foi provocada pelo marido ou companheiro, fato identificado em outro estudo ${ }^{(14)}$. Esta constatação remete ao enfoque da violência conjugal na perspectiva de gênero; o abuso dos homens em relação às suas companheiras é o mais

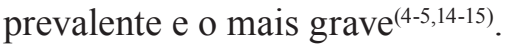

A predominância de casos de violência física vem ao encontro com o citado por outros autores ${ }^{(1,5,14-15)}$ sendo esta a que mais incorre em lesões e requer atendimento médico, sendo frequentemente associada com a violência psicológica, patrimonial ou sexual ${ }^{(1,5,9,14)}$. Os casos de violência psicológica também constituem um achado frequente em instituições sociais de atenção à mulher ${ }^{(1-2,5,14)}$ uma vez que, apesar de não deixar sinal físico, deixa profundas marcas psicológicas sendo, muitas vezes, irreparáveis ${ }^{(14,17)}$.

O tempo ao qual a mulher se submete à agressão corrobora com outros estudos ${ }^{(14-15)}$, os quais mostram 
Quadro 2 - Meio de agressão empregado, região do corpo da vítima atingida e consequência da agressão provocada entre mulheres vítimas de violência, março 2009 - abril de 2010. Pinhais, 2011

\begin{tabular}{|c|c|c|c|c|c|c|c|c|c|c|c|c|c|c|c|c|}
\hline & ÁRE & A DO & CORI & PO ONI & DE A VÍ & ITIMA & $\mathrm{FOIA}$ & TIN & IDA & $\mathrm{CON}$ & ISEQU & ÊNCI & ADO & ATO & IOLE & NTO \\
\hline $\begin{array}{c}\text { Meio } \\
\text { de } \\
\text { agres- } \\
\text { são } \\
\text { empre- } \\
\text { gado }\end{array}$ & $\begin{array}{l}\mathrm{C} \text { a - } \\
\text { beça }\end{array}$ & $\begin{array}{l}\text { Pes- } \\
\text { coço }\end{array}$ & $\begin{array}{c}\mathrm{C} \text { a - } \\
\text { beça } \\
\text { e Tó- } \\
\text { rax }\end{array}$ & $\begin{array}{l}\text { Cabe- } \\
\text { ç a e } \\
\text { Mem- } \\
\text { bros }\end{array}$ & $\begin{array}{l}\text { Mem- } \\
\text { b r o s } \\
\text { Supe- } \\
\text { riores }\end{array}$ & $\begin{array}{c}\text { Mem- }- \\
\text { bros } \\
\text { In fe - } \\
\text { riores }\end{array}$ & $\begin{array}{l}\text { I g - } \\
\text { no- } \\
\text { r a - } \\
\text { do }\end{array}$ & $\begin{array}{c}\text { To } \\
\text { tal }\end{array}$ & $\%$ & $\begin{array}{l}\text { Fra- } \\
\text { tura }\end{array}$ & $\begin{array}{l}\mathrm{He}- \\
\mathrm{m} \mathrm{a}- \\
\text { toma }\end{array}$ & $\begin{array}{l}\text { Cor- } \\
\text { te ou } \\
\text { E n - } \\
\text { torse }\end{array}$ & $\begin{array}{c}\mathrm{Ou}- \\
\text { tra }\end{array}$ & $\begin{array}{ll}\mathrm{I} & \mathrm{g}- \\
\mathrm{n} & \mathrm{o}- \\
\text { rado }\end{array}$ & $\begin{array}{c}\text { To } \\
\text { tal }\end{array}$ & $\%$ \\
\hline $\begin{array}{c}\text { Força } \\
\text { física }\end{array}$ & 6 & 2 & 4 & 11 & 4 & 2 & 9 & 38 & 19 & 4 & 17 & 1 & -- & 16 & 38 & 19 \\
\hline $\begin{array}{c}\text { Enfor- } \\
\text { camen- } \\
\text { to }\end{array}$ & -- & 5 & -- & -- & -- & -- & 1 & 6 & 3 & -- & 2 & -- & -- & 4 & 6 & 3 \\
\hline $\begin{array}{c}\text { A mea- } \\
\text { ça Co- } \\
\text { ação }\end{array}$ & -- & -- & -- & -- & -- & -- & 9 & 9 & 4,5 & -- & -- & -- & 9 & -- & 9 & 4,5 \\
\hline $\begin{array}{l}\text { For ça } \\
\text { física e } \\
\text { Objeto } \\
\text { cortan- } \\
\text { te } \\
\end{array}$ & 2 & -- & -- & 4 & -- & -- & 2 & 8 & 4 & -- & -- & 3 & -- & 5 & 8 & 4 \\
\hline $\begin{array}{l}\text { For ça } \\
\text { fís ica } \\
\text { e En- } \\
\text { forca- } \\
\text { mento e } \\
\text { Objeto } \\
\text { c o r - } \\
\text { tante e } \\
\text { Ameaça }\end{array}$ & -- & -- & -- & 1 & -- & -- & 2 & 3 & 1,5 & -- & -- & -- & 1 & 2 & 3 & 1,5 \\
\hline $\begin{array}{c}\text { Ignora- } \\
\text { do } \\
\end{array}$ & 4 & 3 & 2 & 7 & 5 & 5 & 110 & 136 & 68 & 1 & 4 & 3 & -- & 128 & 136 & 68 \\
\hline Total & 12 & 10 & 6 & 23 & 9 & 7 & 133 & 200 & 100 & 5 & 23 & 7 & 10 & 155 & 200 & 100 \\
\hline$\%$ & 6 & 5 & 3 & 11,5 & 4,5 & 3,5 & 66,5 & 100 & & 2,5 & 11,5 & 3,5 & 5 & 77,5 & 100 & \\
\hline
\end{tabular}

que as mulheres permanecem na relação violenta por sentirem-se econômica e psicologicamente dependentes dos maridos ou companheiros. Também por medo, vergonha de expor sua situação, por acreditarem que o parceiro pode mudar o comportamento e ainda que, o fato de possuírem filhos, pode ser um motivo para a manutenção e melhora na relação. Esta análise culmina com os achados deste estudo o qual evidenciou que a maioria das vítimas possui filhos.

No decorrer do trabalho alguns dados não puderam ser melhores analisados em decorrência de informações incompletas nos registros. Assim, um fato curioso e interessante encontrado foi o alto índice de ausência de respostas a algumas perguntas da ficha de coleta de dados. Como exemplos dessa afirmação têm-se a análise de alguns quesitos como escolaridade, meio de agressão empregado e região anatômica atingida, nos quais as respostas não informadas forma muito frequentes. A falta de informação faz com que as análises apresentem-se aquém do real. A pergunta que se faz da razão deste fato: o que levou estas mulheres a não respondê-las? O medo? Tempo escasso para responder à entrevista? Falta de privacidade/ segurança para responder? Nesse sentido, sugere-se que seja feito um estudo para identificar as razões da ausência de respostas por parte das vítimas a fim de que possam ser propostas ações corretivas. 


\section{CONSIDERAÇÕES FINAIS}

Os resultados deste estudo reiteram que a violência contra a mulher é um fato relevante no município do estudo, pelas características da agressão e do agressor, e das consequências observadas. É necessário o incentivo à mulher em situação de violência a buscar ajuda; os serviços devem ser organizados e respaldados em conhecimento científico para oferecer o suporte necessário à vítima. Ainda, as ações devem garantir a acessibilidade, incluindo o acompanhamento, reabilitação e o tratamento de possíveis danos causado contra a saúde física ou mental.

Os profissionais envolvidos neste processo, dentre eles, o enfermeiro, devem ter uma conduta de amparo e encorajamento para que a vítima procure seus direitos. $\mathrm{O}$ acolhimento é fundamental para a qualidade e a humanização da atenção e pode contribuir para promover o registro completo de informações relevantes para a caracterização desse tipo de violência.

\section{REFERÊNCIAS}

1. Ministério da Saúde (BR). Secretaria Municipal da Saúde de Curitiba. Protocolo de Atenção à Mulher em Situação de Violência. Programa mulher de verdade; 2008.

2. Deeke LP, Coelho EBS, Buchelle F, Boing AF. O resgate do processo do 'cuidado de si' com mulheres inseridas no contexto de violência doméstica. Cogitare enferm. [Internet] 2007;12(3) [acesso em 07 jun 2010]. Disponível: http://ojs.c3sl.ufpr.br/ojs2/index.php/ cogitare/article/view/10527/7085

3. Okabe I. Violência contra a mulher: uma proposta de indicadores de gênero na família [tese]. São Paulo (SP): Universidade de São Paulo; 2010.

4. Silva MCMV. Rota crítica: os (des)caminhos trilhados por mulheres em situação de violência doméstica na busca por ajuda [dissertação]. São Paulo (SP): Universidade de São Paulo; 2008.

5. Ministério da Saúde (BR). Secretaria de Atenção à Saúde. Departamento de Ações Programáticas Estratégicas. Prevenção e tratamento dos agravos resultantes da violência sexual contra mulheres e adolescentes - norma técnica. Série A. Normas e manuais técnicos. Série Direitos Sexuais e Reprodutivos - Caderno 4. Brasília: MS; 2005. [acesso em 22 mar 2010]. Disponível: http://bvsms.saude.gov.br/bvs/ publicacoes/prevencao_agravo_violencia_sexual_ mulheres_3ed.pdf
6. Drezett J. Violência sexual contra a mulher e impacto sobre a saúde sexual e reprodutiva. Revista de Psicologia da UNESP. [Internet] 2003;12(1) [acesso em 20 jan 2010]. Disponível: http://www2.assis.unesp.br/revpsico/ index.php/revista/article/view/13/26

7. Ministério da Saúde (BR). Secretária de Atenção à Saúde. Departamento de ações programáticas estratégicas. Área Técnica de Saúde da Mulher. PréNatal e Puerpério Atenção qualificada e humanizada - manual técnico/Ministério da Saúde, Secretária de Atenção à Saúde. Departamento de Ações Programáticas Estratégicas - Brasília: MS; 2006.

8. Buglione S. Maria da Penha, uma historia banal. Gazeta do Triangulo [Internet] Araguari; 2007 [acesso em 10 out 2009]. Disponível: http://cafehistoria.ning.com/ profiles/blogs/1980410:BlogPost:77147

9. Ministério da Saúde (BR). Secretaria de Políticas de Saúde. Violência intrafamiliar: orientações para práticas em serviço. Brasília: MS; 2001.

10. Dyniewicz AM. Metodologia da pesquisa em saúde para iniciantes. São Caetano do Sul: Difusão; 2007.

11. Lakatos EM, Marconi MA. Fundamentos de metodologia científica. $3^{a}$ ed. São Paulo: Atlas; 1991. p.195-200.

12. Instituto Paranaense de Desenvolvimento Econômico e Social (IPARDES). Caderno Estatístico do Município de Pinhais, 2009 [acesso 28 jun 2010]. Disponível: http://www.ipardes.gov.br/cadernos/Montapdf. php?Municipio $=83320 \& b t O k=o k$

13. Magalhães MN. Noções de probabilidade e estatística. $6^{a}$ ed. São Paulo: Editora da Universidade de São Paulo; 2008.

14. Garcia MV, Ribeiro LA, Jorge MT, Pereira GR, Resende AP. Caracterização dos casos de violência contra a mulher atendidos em três serviços na cidade de Uberlândia, Minas Gerais, Brasil. Cad. Saúde Pública. [Internet] 2008;24(11) [acesso em 07 jun 2010]. Disponível: http://dx.doi.org/10.1590/S0102311X2008001100010

15. Sagim, M, Biasoli AZ, Delfino V, Vanturini F. Violência doméstica: a percepção que as vítimas têm de seu parceiro, do relacionamento mantido e das causas da violência. Cogitare enferm. [Internet] 2007;12(1) [acesso em 22 abr 2009]. Disponível: http://ojs.c3sl.ufpr.br/ojs2/ index.php/cogitare/article/view/8260/5776

16. Ferraz M, Labronici L. Perfil da violência doméstica contra mulher em Guarapuava, Paraná. Cogitare 
enferm. [Internet] 2009;14(2) [acesso em 07 jun 2010]. Disponível: http://ojs.c3sl.ufpr.br/ojs2/index.php/ cogitare/article/view/15612/ 10388

17. Hirigoyen MF. Assédio moral: a violência perversa no cotidiano. 11 ${ }^{\mathrm{a}}$ ed. Rio de Janeiro: Bertrand Brasil; 2009.

18. Minayo MCS, Souza, ER. É possível prevenir a violência? Reflexões a partir do campo da saúde pública. Ciênc. saúde colet. [Internet] 1999;4(1) [acesso em 27 ago 2009]. Disponível: http://redalyc.uaemex.mx/src/ inicio/ArtPdfRed.jsp?iCve $=63013483002$ 